\title{
A Cross-Sectional Study of the Causes, Effects and Management Strategies for Stress and Burnout among Nurses in the Fako Division, Cameroon
}

\author{
Acha Anwi Therese1,2, Ateh Stanislas Ketum³ ${ }^{3}$ Mohamed Isah ${ }^{4,5}$, Thiery Pechap Ayafor6, \\ Agbornkwai Nyenty Agbor ${ }^{7}$, Acha Therese Fomundam Anwi ${ }^{8}$, Malika Esembeson' ${ }^{1}$, \\ Nahyeni Bassah Esoh'
}

\footnotetext{
${ }^{1}$ Department of Nursing, Faculty of Health Sciences, University of Buea, Buea, Cameroon

${ }^{2}$ Department of International Public Health, Liverpool School of Tropical Medicine, Liverpool, UK

${ }^{3}$ Reach Out, Buea, Cameroon

${ }^{4}$ Department of Public Health and Hygiene, Faculty of Health Sciences, University of Buea, Buea, Cameroon

${ }^{5}$ Health Organisation Welfare, Yaounde, Central Region, Cameroon

${ }^{6}$ Department of Epidemiology, School of Public Health, University of Alabama, Birmingham, USA

${ }^{7}$ Family Health International 360, Yaounde, Cameroon

${ }^{8}$ Douala Gynoeco-Obstetrics and Pediatric Hospital, Littoral, Cameroon

Email:anwijunior@gmail.com, atehstanislask@gmail.com, mohamedisahmi@gmail.com, pechap@uab.edu,

a_nyenti@yahoo.com, therese.anwi@gmail.com,ekememalika@yahoo.com,nahyenibassah@yahoo.com
}

How to cite this paper: Therese, A.A., Ketum, A.S., Isah, M., Ayafor, T.P., Agbor, A.N., Anwi, A.T.F., Esembeson, M. and Esoh, N.B. (2020) A Cross-Sectional Study of the Causes, Effects and Management Strategies for Stress and Burnout among Nurses in the Fako Division, Cameroon. Journal of Biosciences and Medicines, 8 , 17-27.

https://doi.org/10.4236/jbm.2020.87002

Received: February 21, 2020

Accepted: July 12, 2020

Published: July 15, 2020

Copyright $\odot 2020$ by author(s) and Scientific Research Publishing Inc. This work is licensed under the Creative Commons Attribution International License (CC BY 4.0). http://creativecommons.org/licenses/by/4.0/

\begin{abstract}
Introduction: Stress and burnout are a reality which nurses encounter and try to cope with especially in the Emergency Department (ED) so that they can provide optimal patient care. Nurses who work in ED are front line providers of immediate medical care needed to stabilize patients. With the known critical shortage of health workforce in Cameroon, nurses are overloaded with work and often experience stress and burnout. Aim: This study aimed at determining the causes, effects and management strategies of stress and burnout among nurses working in the ED in hospitals in the Fako Division, Cameroon. Methods: This study was a descriptive cross-sectional study. The sample consisted of seventy nurses from five different hospitals. A purposive sampling technique was used and data was analyzed using SPSS version 16.0. Data was collected using a structured questionnaire developed from the International Stress Management Scale. Results: The highest reported cause of stress in this study was heavy workload (12.88\%) and the least was no experience in handling the challenges of the department. The leading reported effect of stress was the development of musculoskeletal disorders such
\end{abstract}


as joint and back pain (16.48\%) and the least effect was contemplating quitting the profession (5.99\%). The major management strategy used was humour (8.27\%), while the least was crying out stress to feel relieved (2.18\%). Conclusion: The major cause of stress and burnout among nurses in our study setting was heavy workload, which mostly results in joint and back pain. Moreover, humour was the prime management strategy for stress and burnout among nurses in the emergency department in the study setting. Thus more nurses should be employed and the working conditions of nurses improved to reduce the workload in the study hospitals.

\section{Keywords}

Stress, Burnout, Nurses, Causes, Effect and Management, Cameroon

\section{Introduction}

Nursing is inevitably a demanding and stressful job [1]. The healthcare sector is known to be a stressful industry with manpower shortage and high demands. Compared to other healthcare professionals, nurses are the first line of contact, the most engaged with patients and are always exposed to the emotional strains of catering for the sick and dying, with most of them tirelessly working in Emergency Departments (EDs) [2]. When such stressors are left unchecked and unmanaged, it might lead to stress and burnout [2].

Stress in nursing is a mental and physical response and adaptation by the nurse to the real or perceived changes and challenges faced in their job. A stressor is any real or perceived physical, social or psychological event or stimulus that causes our body to react or respond [3]. There exist a relationship between stress and burnout and proven by the fact that prolonged stress leads to burnout [4]. That is, if the stress continues to operate on a full scale for an extended period, there is an increased risk for burnout. Burnout in nursing, on the other hand, is a condition where nurses experience chronic fatigue, exhaustion, and frequent headaches on account of work stress, affecting professional performance. Nurse burnout has three basic features which are; emotional exhaustion, depersonalization and poor personal achievement [5]. This showcases the fact that nurses are leaving the profession due to occupational stress and inability to provide nurse-assessed good quality care [6].

Globally, nurses comprise the group that experiences the maximum stress and burnout among healthcare professionals. In Africa, the situation is a more serious concern due to shortages of healthcare professionals [1]. Likewise, Cameroon described as one of the 57 countries with "critical shortages" of healthcare workers [7] has an estimated health workforce density of 1.3:1000; which is under the WHO recommended of 2.5:1000 [8]. The country has an estimated physician to population density of 1:12,500 [9] and 1:26,726 in some regions [8]. There is a similar situation with the nursing work-force especially in the emer- 
gency department with a nurse to population density of 0.67 per 1000 [8]. With such critical shortage of nurses, there is a high expectation and workload for the available few. Thus, nurses are at risk of having stress and automatically burnout syndrome in Cameroon. This study thus sought to determine the causes, effects and management strategies of stress and burnout among nurses working in the Emergency Department in some hospitals in the Fako Division so as to attract policy makers and hospital administrators' concern and assistance.

\section{Materials and Methods}

\subsection{Study Design}

This study was a descriptive cross-sectional design carried out from December 2016 to June 2017.

\subsection{Study Area and Setting}

This study was carried out in selected hospitals in the Fako Division. These hospitals are the major hospitals in Fako and they have emergency departments. The Fako Division is located in South West Region with headquarters in Limbe. It occupies an area of $2093 \mathrm{~km}^{2}$ and inhabits a total population of 534,854 people. It is divided administratively into 7 councils which are; Buea, Limbe I, Limbe II, Limbe III, Muyuka, Tiko and West Coast. The selected hospitals are located in the following towns; Buea, Tiko, Mutengene, Limbe.

\subsection{Study Population and Sampling}

The study population comprised all nurses who work in Emergency Departments in five (5) hospitals in the Fako Division. This study made use of a purposive sampling technique. This is a non-probability sampling method which is selected based on the characteristics of a population and the objectives of the study, where sampling for proportionality is not the main concern [10]. Also, the purposive sampling method used is total population purposive sampling which examines the entire population which has one or more shared characteristics common to a particular group or groups within larger populations [10].

This study, therefore sampled hospitals based on a common characteristic of having an emergency department and all nurses who work in the ED. Nurses who worked full-time in the ED and nurses who had worked in the ED for at least six months were included in the study.

\subsection{Instrumentation and Study Procedure}

A well-structured questionnaire was used as the main tool for data collection. The questionnaire was structured to first collect demographic information about the participants. The later part of the questionnaire was divided into three parts with each part containing at least twelve questions based on the three specific objectives of the study (Causes, Effects, and Management strategies). Closedended questions were used as well as one open-ended question at the end of each 
objective to assess the factors not listed in the questionnaire. Each of the questions on the three parts of the questionnaire had 4 responses graded from 1 to 4 ( 1 = very low, 2 = low, 3 = high, $4=$ very high). To assess the level of stress, a stress scale guided by the International Stress Management Scale [11] was used. This scale assessed the objectives as follows.

For causes of stress, after adding up the responses for each cause, everyone who scored a total of $\leq 7$ had the least causes of stress and as such had a lower risk of developing stress-related illness 8 - 23 was more likely to experience stress-related illness $>24$ was most prone to experiencing stress showing a greater number of characteristics and suffered from stress-related illnesses.

For the effects of stress, after adding up the responses for each effect, everyone who scored a total of $\leq 6$ felt the least effects of stress. 7 - 19 were more likely to experience the effects of stress. $>20$ were most prone to experiencing the effects of stress.

For management:

$\leq 11$ least management strategies used.

12 - 34 make more use of management strategies.

$>35$ make the most use of management strategies.

A total number of 73 questionnaires were administered with a $95.89 \%$ response rate. In the end, 3 questionnaires were rejected due to incomplete responses giving a non-response rate of (4.29\%). The nature of the distribution of the questionnaires was based on the number of ED nurses in each hospital.

\subsection{Data Analysis and Management}

Data was analyzed using SPSS version 16.0. Demographic data (gender, age, marital status, educational qualification number of working hours per week, years of experience, number of night shifts, post of responsibility and shifts with more work) was arranged in a tabular form for all the hospitals and represented in pie and bar charts. For each objective, the number of responses was put in tabular form under the headings very low, low, high and very high, as well as their respective percentages were also represented in a tabular form. The mean, mode and median for each objective were represented. At the end, a table showing the causes, effects and management strategies of stressed and burnout was presented. The values of each measure presented used the Stress Management Scale as a reference or gold standard.

\section{Results}

\subsection{Demographic Characteristics}

Table 1 is summary of the demographic data.

\subsection{Causes of Stress in the Emergency Department}

Table 2 shows perceived causes of stress according to the International Stress Management Scale. 
Table 1. Summary of demographic data.

\begin{tabular}{|c|c|c|c|c|c|c|c|c|c|c|c|c|c|c|}
\hline \multicolumn{2}{|c|}{ Gender } & \multicolumn{4}{|c|}{ Age Group } & \multicolumn{4}{|c|}{ Marital Status } & \multicolumn{5}{|c|}{ Level of Education } \\
\hline MALE & FEMALE & $20-30$ & $31-40$ & $41-50$ & $51-60$ & Single & Married & Widow & Divorced & $\mathrm{N}-\mathrm{A}$ & SRN & HND & BSc & Masters \\
\hline 13 & 57 & 34 & 23 & 13 & 0 & 34 & 35 & 1 & 0 & 19 & 18 & 17 & 12 & 4 \\
\hline
\end{tabular}

Table 2. Causes of stress.

\begin{tabular}{ccccc}
\hline Perceived Causes & Very low & Low & High & Very high \\
\hline Heavy Workload & 2 & 5 & 31 & 32 \\
Verbal and Physical Assault & 12 & 19 & 19 & 20 \\
Limited Time of Nursing Intervention & 16 & 20 & 16 & 18 \\
Confronted with Broad Range of Health Conditions & 14 & 10 & 16 & 30 \\
Frustration from Patients and Relatives & 6 & 18 & 17 & 29 \\
$\quad$ No Breaks during Shift & 21 & 5 & 9 & 35 \\
Complex Medical Conditions (which are emotionally & 13 & 11 & 23 & 23 \\
$\quad$ demanding) & 27 & 20 & 8 & 15 \\
No Experience in Handling Critically Ill Patients & 16 & 5 & 30 & 19 \\
Low Salaries Compared to Workload & 10 & 8 & 12 & 40 \\
Exposure to Health Hazards & 11 & 12 & 18 & 29 \\
Lack of Equipment &
\end{tabular}

\subsection{Effects of Stress in the Emergency Department}

Table 3 shows perceived effects of stress according to the International Stress Management Scale.

Table 3. Effects of stress.

\begin{tabular}{ccccc}
\hline Perceived Effects & Very Low & Low & High & Very High \\
\hline Contemplate quitting job & 35 & 15 & 10 & 10 \\
Memory loss and poor decision making & 16 & 20 & 20 & 14 \\
Headaches and extreme fatigue & 6 & 14 & 17 & 33 \\
High blood pressure & 16 & 30 & 9 & 15 \\
Development of gastritis & 18 & 15 & 14 & 23 \\
General disappointment with life & 21 & 28 & 11 & 10 \\
Altered character (anger and hostility) & 23 & 21 & 13 & 13 \\
$\begin{array}{c}\text { No balance between work and personal life } \\
\text { Musculoskeletal disorders }\end{array}$ & 16 & 17 & 10 & 27 \\
Disturbed emotional and psychological state & 11 & 29 & 14 & 16 \\
\hline
\end{tabular}




\subsection{Management of Stress in the Emergency Department}

Table 4 shows management of stress according to the International Stress Management Scale.

Table 4. Management of stress.

\begin{tabular}{ccccc}
\hline Management & Very Low & Low & High & Very High \\
\hline Identifying area of stress & 9 & 9 & 20 & 32 \\
Do more research & 13 & 15 & 24 & 18 \\
Social support from friends and family & 5 & 21 & 15 & 29 \\
Physical exercise & 13 & 12 & 15 & 30 \\
Using humor & 10 & 7 & 27 & 26 \\
Reading interesting novels & 28 & 24 & 7 & 11 \\
Listening to music & 4 & 21 & 17 & 28 \\
Regular meditation and thinking & 20 & 14 & 20 & 16 \\
Frequent massage & 25 & 16 & 22 & 7 \\
Watching Television & 15 & 15 & 21 & 19 \\
Spending time on hobby & 10 & 15 & 25 & 20 \\
Adequate rest & 11 & 10 & 9 & 40 \\
Drink much or binge feeding & 26 & 20 & 12 & 12 \\
Avoiding panic & 10 & 14 & 16 & 30 \\
Psychosocial counseling & 16 & 28 & 13 & 13 \\
Ignore stress & 19 & 18 & 18 & 15 \\
Cry out stress & 6 & 50 & 3 & 11 \\
\hline & & & & \\
\hline & 10 & 28 & 25 \\
\hline
\end{tabular}

\section{Discussion}

The results from the study of causes of stress and burnout among nurses in the ED in some hospitals in the Fako division revealed that $12.88 \%$ of the nurses cited heavy workload as the leading cause of stress. This finding is similar to the results of a study carried out in Ghana, which listed heavy workload as the leading cause of stress [12]. Furthermore, another study noted that poor working conditions and heavy workload were the leading causes of stress among nurses [13]. From this study, $9.61 \%$ of nurses do experience stress as a result of a lack of equipment. Similar findings were observed among nurses in Turkey where nurses reported that they were stressed due to inadequacy of equipment [14]. In both settings, nurses were forced to improvise methods of care and were exposed to health hazards. Also, our study revealed that $7.98 \%$ of nurses were stressed out as a result of verbal and physical assault from patients and their relatives. This finding is similar to that of another study which showed that nurses in the emergency department and the intensive care unit faced more stressed than nurses from other departments owing to verbal and physical assault from patients and 
their relatives [15]. Moreover, 9.41\% of nurses were stressed due to handling complex medical conditions which were emotionally demanding. This finding is analogous to that of a study, which observed that ED nurses were stressed due to dealing with major incidents, death and resuscitation of patients [16]. Furthermore, conditions of patients are constantly changing and the work in the ED is very unpredictable. For this reason, nurses get confronted with a broad range of conditions and problems which need mix skills. It is, therefore, important for hospitals to recruit unlicensed less specialized staff to undertake tasks that do not necessarily need a registered nurse to perform. This leads to increased productivity, greater work satisfaction and cost effectiveness by decreasing work pressures and allowing nurses to focus on maximizing nursing care [17].

The major effect of stress from the result of this study is the development of musculoskeletal disorders such as joint pain and back pain. $16.48 \%$ of nurses suffered this condition as result of bending, lifting patients and standing for long hours during their shifts at the hospital. This is consistent with the results gotten from a study in Finland where ED nurses reported musculoskeletal disorders as the main effect of stress and burnout [17]. This is quite different from the results gotten from Clark (2012) whose main effect of stress was feelings of fatigue and liable to making medical errors [18]. Moreover, $14.97 \%$ of nurses complained of developing headache frequently as a result of stress. This finding is in agreement with that of a study carried out in Dutch which reported that stress and burnout cause poor health and psychological illnesses (such as headaches), impairment of immunological system, and gastroenteritis [19]. Up to $10.18 \%$ of nurses in this study reported loosing concentration as an effect of burnout. This can result in poor decision making and negligence to identify work-related errors. This is in line with the finding that linked increase burnout to increase nosocomial infection in acute care facilities [20]. Some nurses (5.99\%) in this study felt frustrated and contemplated quitting their job as a result of stress and burnout. Similar studies reported that nurses faced overwhelming exhaustion, detachment from their jobs, a sense of ineffectiveness and lack of accomplishment as a result of stress [21].

$8.27 \%$ of nurses used humour to overcome stress; that is, they used humour as a stress management strategy [22]. This finding is quite different from a previous study whose major management strategy was carrying out regular physical activities as a means to restore energy and a sense of wellbeing [23]. The fact that women make up the vast majority of the population of nurses and being generally less physically active than men can partially explain this disparity. They tend to prefer discussions and socializing as a means of relaxation rather than vigorous physical activity [24].

\section{Limitation to the Study}

1) The participants were confronted just once; there is a possibility that multiple encounters could have reduced the effect their moods at work could have 
had on their responses.

2) A larger sample size could strengthen the implications of our findings.

\section{Conclusion}

Based on the findings, the leading cause of stress is heavy workload and the least cause of stress comes from having little or no experience in handling the critically ill and facing the challenges of the department. Also, the major effect of stress and burnout is the development of musculoskeletal disorders and the least effect is contemplating quitting the profession. The most used management strategy was humour and the least used was crying out one's stress. Although a small amount of stress is needed to keep these nurses alert, there are levels that should be avoided because it becomes a danger to their health and can compromise the care rendered to patients. Therefore, hospital administrators should urgently address this issue. ED nurses should also learn to manage stress properly.

\section{Availability of Data and Materials}

The dataset and materials of the study are available through the author AAT and will be made accessible on request at the following e-mail: anwijunior@gmail.com

\section{Funding}

No external Funding.

\section{Acknowledgements}

Our immense thanks go to the Delegation of Public Health of the South West Region for their cooperation and support.

\section{Authors' Contributions}

ATA participated in conception, literature review, data collection, data management, data analysis and interpretation. ASK participated design, drafting, and correction of the final manuscript. MI participated in the conception, design, data management, data analysis, drafting and revising the manuscript for publication, TPA: participated in drafting, data management and analysis, ANA participated in data collection, data management and interpretation, ATFA participated in conception, literature review and interpretation of results, ME participated in conception, design and review of the academic content, NBE participated in conception, design and reviewed of the academic content. All authors read and approved the final copy.

\section{Conflicts of Interest}

The authors declare no conflicts of interest regarding the publication of this paper. 


\section{References}

[1] Grubb, P.L., Grosch, J.W. and Roberts, R. (2012) Alleviating Job Stress in Nurses: Approach to Reducing Job stress in Nurses. https://www.cdc.gov/niosh/nioshtic-2/20042107.html

[2] Aiken, L.H., Clarke, S.P., Sloane, D.M., Sochalski, J.A., Busse, R., Clarke, H., et al. (2001) Nurses' Reports on Hospital Care in Five Countries. Health Affairs (Millwood), 20, 43-53. https://doi.org/10.1377/hlthaff.20.3.43

[3] American Psychological Association (2010) Stress in America. https://www.apa.org/news/press/releases/stress

[4] Maaroufi, N., Rzeigui, J., Ayari, L., Abid, Z., et al. (2015) Assessment of the Effects of Stress among Health Care Providers at the Tabarka and Jendouba General Hospital's Emergency Service Units in Northern Tunisia. Scientific Research Publishing, 7, 910-914. https://www.scirp.org/journal/health https://doi.org/10.4236/health.2015.78107

[5] Darawad, M.W., Nawafleh, H., Maharmeh, M., Ayman, M. and Saleh, N.A. (2015) The Relationship between Time Pressure and Burnout Syndrome: A Cross Sectional Survey among Jordanian Nurses. Health, 7, 14-22.

https://www.scirp.org/journal/health https://doi.org/10.4236/health.2015.71003

[6] Kennedy, M. (2016) Emergency Department Workers Face High Stress, Burnout. Reuters Health.

https://www.reuters.com/article/us-health-stress-emergency-department-idUSKBN $\underline{13 \mathrm{C} 2 \mathrm{AD}}$

[7] Global Health Work Force (2013) Health Workers for All and All for Health Workers: The Human Resource for Health Crisis. World Health Organization, Geneva.

[8] Tandi, T.E., Cho, Y., Akam, A.J., Afoh, C.O., Ryu, S.H., Choi, M.S., et al. (2015) Cameroon Public Health Sector: Shortage and Inequalities in Geographic Distribution of Health Personnel. International Journal Equity Health, 14, 43.

[9] Agency TWFCI. Africa: Cameroon 2017. https://www.cia.gov/library/publications/the-world-factbook/geos/cm.html

[10] Crossman, A. and Nicki, L.C. (2020) Understanding Purposive Sampling. ThoughtCo, 1-2. https://www.thoughtco.com/purposive-sampling-3026727

[11] Chinawa, J., Chinawa, A., Aniwada, E. and Amadi, O. (2015) Prevalence and Factors Associated with Susceptibility to Stress Related Illnesses among Medical Students in a Nigerian Medical School. International Journal of Medicine and Health Development, 20, 19-25.

[12] Assibi, A.R., Atindanbilgo, S., Mwini-Nyaledzigbor, P.P. and Abepuoring, P. (2013) The Causes of Stress and Job Dissatisfaction among Nurses at Ridge \& Pantang Hospitals in Ghana. International Journal of Asian Social Science, 3, 762-771. https://www.aessweb.com/journal-detail

[13] Grubb, P.L. and Rashaun, K.R. (2015) The Consequences of Nursing Stress and Need for Integrated Solutions. Rehabilitation Nurses, 39, 62-69. https://doi.org/10.1002/rnj.97

[14] Isikhan, V., Comez, T. and Danis, M.Z. (2004) Job Stress and Coping Strategies in Health Care Professionals Working with Cancer Patients. European Journal of Oncology Nursing, 8, 234-244. https://doi.org/10.1016/j.ejon.2003.11.004

[15] Admed, A.S. (2012) Verbal and Physical Abuse against Jordanian Nurses in the Work Environment. Eastern Mediterranean Health Journal, 18, 318-324. 
https://doi.org/10.26719/2012.18.4.318

[16] Healy, S. and Tyrrell, M. (2011) Stress in Emergency Departments: Experiences of Nurses and Doctors. Emergency Nurse Journal, 19, 31-37. https://doi.org/10.7748/en2011.07.19.4.31.c8611

[17] Berlin, M., G., English, C.R., Higgins, H. and Lapointe, M., (2014) Optimizing the Nursing Skill Mix: A Win for Nurses, Patients, and Hospitals. McKinsey on Healthcare.

https://www.mckinsey.com/industries/healthcare-systems-and-services/our-insights loptimizing-the-nursing-skill-mix--a-win-for-nurses-patients-and-hospitals\#

[18] Clark, M., Schmitz, GR., Heron, S., Sanson, T., et al. (2012) Strategies for Coping with Stress in Emergency Medicine: Early Education Is Vital. Journal of Emergencies, Trauma and Shock, 5, 64-69. https://doi.org/10.4103/0974-2700.93117

[19] Mohren, C.L., Swaen, G., Kant, I. and Amelsvoort, L (2003) Common Infections and the Role of Burnout in Dutsch Working Population. Journal of Psychosomatic Research, 55, 201-208. https://doi.org/10.1016/S0022-3999(02)00517-2

[20] Cimiotti, J.P., Aiken, L.H., Sloane, D.M. and Wu, E.S. (2012) Nurse Staffing Burnout and Health Care-Associated Infection. American Journal of Infection Control, 40, 486-490. https://doi.org/10.1016/j.ajic.2012.02.029

[21] Leiter, M.P. and Maslach, C. (2016) Understanding the Burnout Experience: Recent Research and Its Implications for Psychiatry. Official Journal of the World Psychiatric Association, 15, 103-111. https://doi.org/10.1002/wps.20311

[22] Rice, V., Glass, N., Ogle, K.R. and Parsian, N. (2014) Exploring Physical Health Perception, Fatigue and Stress among Health Care Professionals. Journal of Multidisciplinary Healthcare, 7, 155-161. https://doi.org/10.2147/JMDH.S59462

[23] Honkonen, T., Ahola, K., Isometsa, E., Kalimo, R., et al. (2006) Burnout in the General Population. Results from the Finnish Health 2000 Study. US National Library of Medicine National Institute of Health, 41, 11-17. https://doi.org/10.1007/s00127-005-0011-5

[24] Rogers, N. (2009) Lifelong Gender Difference in Physical Activity Revealed. ScienceDaily-The A-CLASS Project. https://www.sciencedaily.com/releases/2009/01/090105190740.htm 


\section{Abbreviations}

AIS: American Institute of Stress

APA: American Psychological Association

ANS: Autonomic Nervous System

BHM: Baptist Hospital Mutengene

DHL: District Hospital Limbe

DHT: District Hospital Tiko

ED: Emergency Department

EMJ: Emergency Medical Journal

ENA: Emergency Nurses Association

ILO: International Labor Organisation

ISMA: International Stress Management Association

MCN: Michigan Center for Nurses

NHS: National Health Services

PNS: Parasympathetic Nervous System

RCN: Royal College Nurses

RHB: Regional Hospital Buea

RHL: Regional Hospital Limbe

SNS: Sympathetic Nervous System

NA: Nursing Assistant

SRN: State Registered Nurse

HND: Higher National Diploma

BSc: Bachelor of Science

AAT: Acha Anwi Therese

ASK: Ateh Stanislas Ketum

MI: Mohamed Isah

TPA: Thiery Pechap Ayafor

ANA: Agbornkwai Nyenty Agbor

ATFA: Acha Therese Fomundam Anwi

ME: Malika Esembeson

NBE: Nahyeni Bassah Esoh 